\section{RMD Open}

Rheumatic \&

Musculoskeletal Diseases

\title{
Osteoporosis prevention among chronic glucocorticoid users: results from a public health insurance database
}

Sophie Trijau, ${ }^{1}$ Gaëlle de Lamotte, ${ }^{1,2}$ Vincent Pradel, ${ }^{3}$ François Natali, ${ }^{4}$ Véronique Allaria-Lapierre, ${ }^{4}$ Hervé Coudert, ${ }^{4}$ Thao Pham, ${ }^{1,2}$ Vincent Sciortino, ${ }^{4}$ Pierre Lafforgue $e^{1,2}$

To cite: Trijau S, de Lamotte G, Pradel V, et al. Osteoporosis prevention among chronic glucocorticoid users: results from a public health insurance database. RMD Open 2016;2:e000249. doi:10.1136/rmdopen-2016000249

- Prepublication history and additional material for this paper is available online. To view these files please visit the journal online (http://dx.doi.org/10.1136/ rmdopen-2016-000249).

- Additional material is published online only. To view please visit the journal online (http://dx.doi.org/10. 1136/rmdopen-2016000249).

Received 15 January 2016 Revised 9 May 2016 Accepted 12 May 2016

CrossMark

For numbered affiliations see end of article.

Correspondence to Professor Pierre Lafforgue; pierre.lafforgue@ap-hm.fr

\section{ABSTRACT}

Introduction: Long-term glucocorticoid therapy is the leading cause of secondary osteoporosis. The management of glucocorticoid-induced osteoporosis (GIOP) seems to be inadequate in many European countries.

Objective: To evaluate the rate of screening and treatment of GIOP.

Design: Information was collected from a national public health-insurance database in our geographic area of Provence-Alpes-Côte-d'Azur and in Corsica, from September 2009 through August 2011.

Patients: We identified participants aged 15 years and over starting glucocorticoid therapy $(\geq 7.5 \mathrm{mg}$ of prednisone equivalent per day during at least 90 days consecutive). This cohort was compared with an agematched and sex-matched population that did not receive glucocorticoids.

Main outcome measures: Bone mass, prescription of bone antiresorptive medication and use of calcium and/or vitamin $\mathrm{D}$ treatment.

Results: We identified 32812 patients who were prescribed glucocorticoid therapy, yielding $1 \%$ prevalence. Incidence of glucocorticoid therapy was 2.8/1000 inhabitants/year. Males represented $44 \%$, the mean age was 58 years. The median prednisone-equivalent dose was $11 \mathrm{mg} /$ day (IQR 9-18 mg/day). 8\% underwent bone mass measurement. Calcium and/or vitamin D, and bisphosphonates were prescribed in $18 \%$ and $12 \%$, respectively. Results were lower for the control population: $3 \%$ underwent bone mass measurement and $3 \%$ received bisphosphonate therapy. The rates of osteodensitometry and treatments were higher in women over 55 years of age than in men and women 55 years of age and younger, and also when glucocorticoid therapy was initiated by a rheumatologist versus other physician specialty.

Conclusions: The management of GIOP remains very inadequate, despite the availability of a statutory health insurance system. Targeted interventions are needed to improve the management of GIOP.

\section{INTRODUCTION}

Long-term glucocorticoid therapy is the leading cause of secondary osteoporosis.

\section{Key messages}

What is already known about this subject?

- Long-term glucocorticoid therapy is common and is the leading cause of secondary osteoporosis.

What does this study add?

- Information from a national public health-insurance database confirm that management of glucocorticoid- induced osteoporosis is currently inadequate.

How might this impact on clinical practice?

- Primary care physicians should be better informed of their crucial role in prevention and management glucocorticoid-induced osteoporosis.

Glucocorticoids are widely prescribed, with about $0.5-1.2 \%$ of adults in the general population being on long-term glucocorticoid therapy, ${ }^{1-3}$ and this prevalence increases with age. Glucocorticoid prescriptions have actually increased between 1989 and 2008 in UK. $^{3}$ Glucocorticoid-induced osteoporosis (GIOP) has been associated with substantial morbidity related to major fracture. The relative risk of fracture is significantly increased even at low glucocorticoid dosages. ${ }^{4} 5$ Glucocorticoids decrease bone formation and increase bone resorption, which, 3 months after the beginning of treatment, leads to bone fragility. ${ }^{6}$ The main causes for being on glucocorticoid therapy are inflammatory rheumatic diseases, lung disorders and inflammatory bowel diseases. ${ }^{3}$ The underlying inflammation for which glucocorticoids are used also influenced bone fragility-bone loss is related to inflammation. ${ }^{7}$

Management of GIOP is not optimal worldwide. $^{8}$ Many countries have issued national recommendations for minimising the risk of GIOP via both primary prevention at treatment initiation and secondary 
prevention in patients with pre-existing osteoporosis. An example is the set of guidelines developed by the American College of Rheumatology in 2001 and updated in 2010. ${ }^{10}$ Specifically in France, prevention of GIOP must be considered as soon as possible in men and women for whom corticosteroid therapy equivalent to $\geq 7.5 \mathrm{mg}$ prednisone daily for $\geq 3$ months is scheduled. In these patients, osteodensitometry (dual-energy X-ray absorptiometry, DXA) and daily calcium $1500 \mathrm{mg}$ and vitamin D 800 UI are recommended. Pharmacological treatment is indicated for those with a history of fragility fracture or, if absent, in those with T-score $<-1.5$ SD. ${ }^{11} 12$ These recommendations changed lately. ${ }^{13}$

Unfortunately, there is abundant evidence from various countries that the management of GIOP remains suboptimal, but data from France are lacking.

We hypothesised that the management of GIOP was less than ideal in our region of France (Provence-AlpesCôte-d'Azur and Corsica). To assess this hypothesis, we used claims data from the statutory health insurance system, to evaluate the rate of detection and treatment of GIOP. DXA is not mandatory and is insufficient to assess bone fragility in GIOP. In French 2003 recommendations, only menopausal women with fragility fracture should be prescribed with antiosteoporotic drugs without DXA. For all other cases (men, women before menopause, women after menopause without fragility fracture) DXA measurement is required. So DXA measurement is tightly associated with the physician implication in GIOP management.

\section{METHODS}

\section{Claims database}

We used the claims database of the French statutory health insurance system, which covers most past and present salaried workers, and the unemployed, and their families, that is, about 4.1 million individuals and $83 \%$ of the population, in our geographic area of Provence-Alpes-Côte-d'Azur and Corsica. The data were extracted by health insurance physicians in the region. None of the extracted data contained information on patient or physician identity.

The following data were collected: coded identifiers of the patient and prescribing physician, sociodemographic information on the patient and prescribing physician, details on the delivery of glucocorticoids and other medications of interest, and whether DXA was performed. Prescribing physicians' specialty was available in the databases except for those working in publicly funded hospitals; for our study, their specialties were therefore recorded as unknown. As the study databases were de-identified, patient informed consent was not required.

\section{Study population}

Among the individuals in the database, those aged 15 years or over who had at least two prescriptions for glucocorticoids filled between 1 September 2009 and 31 August 2011, were identified. Then, we selected those individuals with prescriptions for oral therapy with prednisone, prednisolone, methylprednisolone, betamethasone and/or dexamethasone. The next step was selecting patients with prescriptions of at least a $7.5 \mathrm{mg}$ prednisone-equivalent per day for at least 90 consecutive days (prevalent cases of long-term glucocorticoid therapy). Finally, we identified the incident cases of long-term glucocorticoid therapy, defined as those prevalent cases who did not fill glucocorticoid prescriptions during the first 6 months of the 24-month study period. Thus, patients younger than 15 years, taking non-oral route glucocorticoids, taking a prednisone-equivalent dosage lower than $7.5 \mathrm{mg} /$ day, with glucocorticoid treatment duration shorter than 90 days, or with glucocorticoid prescription filled during the first 6 months of the study period, were not included. Each incident case was matched on age and sex to a control, defined as an individual in the database who had no filled oral glucocorticoid prescriptions during the study period.

\section{Study variables}

In the cases, we collected the following data: age, sex, daily glucocorticoid dosage, glucocorticoid treatment duration, specialty of the first physician to prescribe glucocorticoid therapy and reason for glucocorticoid therapy (defined as the chronic disease status granted by the health insurance system in response to a request from the primary care physician).

We used administrative data to compare rates of bone mass measurement evaluated by DXA, and osteoporosis treatment in cases and controls between 1 September 2009 and 31 August 2011. For this study, osteoporosis treatments were defined as calcium associated with vitamin D supplements (which could be separately given as oral solution or fixed combination with alendronate, for instance) and as any of the following osteoporosis medications: bisphosphonates, raloxifene, teriparatide and strontium ranelate. Our list of osteoporosis medications did not include calcitonin and oestrogens, as they are not approved for the treatment of osteoporosis in France.

\section{Statistics}

Qualitative variables were described using number (\%) and quantitative variables using mean $\pm \mathrm{SD}$ when distribution was normal and median (IQR) otherwise. Kaplan-Meier curves were plotted to estimate glucocorticoid treatment duration.

To identify variables independently associated with DXA and osteoporosis treatment, we built a multivariate logistic regression model and computed the adjusted ORs (aORs). The variables we used were sex, age, specialty of glucocorticoid prescriber, mean dosage, underlying diagnosis and DXA prescription. Treatments were analysed as three categories: calcium associated with vitamin $\mathrm{D}$; bisphosphonates (the other osteoporosis medications being in very small amounts); and any 
treatment, that is, calcium, vitamin $\mathrm{D}$ and/or any osteoporosis treatment drug. We performed $\chi^{2}$ tests and Fisher tests on categorical variables. Statistical tests $\left(\chi^{2}\right.$ tests and Fisher tests) on categorical variables were performed. To evaluate whether dosage of prednisone of prednisone influenced the rate of bisphosphonates prescription, we split the prednisone dosage in five classes (7.5-10; 10-15; 15-20, 20-30 and more than $30 \mathrm{mg})$ and conducted a $\chi^{2}$ test for trend.

\section{RESULTS}

\section{Study population}

Of the 3.3 million individuals aged at least 15 years in the database, $518853 \mathrm{had}$ at least two glucocorticoid prescriptions filled during the study period, including 32812 with filled prescriptions in a dosage of at least $7.5 \mathrm{mg} /$ day and for at least 90 consecutive days, yielding a prevalence of $1 \%$ of longstanding glucocorticoid therapy (figure 1). Of these 32812 patients, 14205 (43\%) met our definition of incident cases, yielding an incidence of $0.4 \%$ for 18 months in the overall population aged at least 15 years, corresponding to an incidence of long-term glucocorticoid therapy of 2.8/1000 inhabitants/year (assuming that incidence rate is constant during the study).

Of the 14205 cases, 6311 (44\%) were males and 7894 (55\%) females, including 4377 (31\%) females older than 55 years. Mean age was $58 \pm 19$ years overall, 58 \pm 18 years were males and $57 \pm 20$ years were females. Median glucocorticoid dosage was $11 \mathrm{mg} /$ day (IQR
$9-18 \mathrm{mg} /$ day) of prednisone equivalent and varied very little with age and sex. Median glucocorticoid treatment duration was 206 days (95\% CI 202 to210 days).

\section{Prescriptions of absorptiometry and treatments}

DXA was performed during the study period in 1175 $(8 \%)$ cases and $251(3 \%)$ controls $\left(\mathrm{p}<10^{-6}\right)$. Osteoporosis treatments (vitamin D and/or calcium and/or osteoporosis medications (bisphosphonates, raloxifene, teriparatide, strontium ranelate)) were prescribed in combination with glucocorticoid therapy in $36 \%$ of cases and $11 \%$ of controls $\left(p<10^{-6}\right)$. Prescribed supplements were distributed as follows: calcium, $20 \%$ of cases and $5 \%$ of controls $\left(\mathrm{p}<10^{-6}\right)$; vitamin $\mathrm{D}, 32 \%$ and $11 \%\left(\mathrm{p}<10^{-6}\right)$; and both, $18 \%$ and $4 \% \quad\left(\mathrm{p}<10^{-6}\right)$. Bisphosphonate therapy was prescribed in $12 \%$ of cases and $3 \%$ of controls $\left(\mathrm{p}<10^{-6}\right)$. Other osteoporosis medications rate was very low: $1.7 \%$ of cases used ranelate, $0.2 \%$ teriparatide and $0.5 \%$ raloxifene. Table 1 reports details on DXA, supplements and osteoporosis medications prescription.

\section{Prescribers and reasons for prescription of glucocorticoid therapy}

The first glucocorticoid prescription filled by the cases was prescribed by primary care physicians in 55\% of cases, rheumatologists in 5\%, pulmonologists in $2 \%$, gastroenterologists in $2 \%$ and internists in $1 \%$ of cases. Prescriber's specialty was unknown in $23 \%$ of cases, suggesting that glucocorticoid therapy was initiated at a

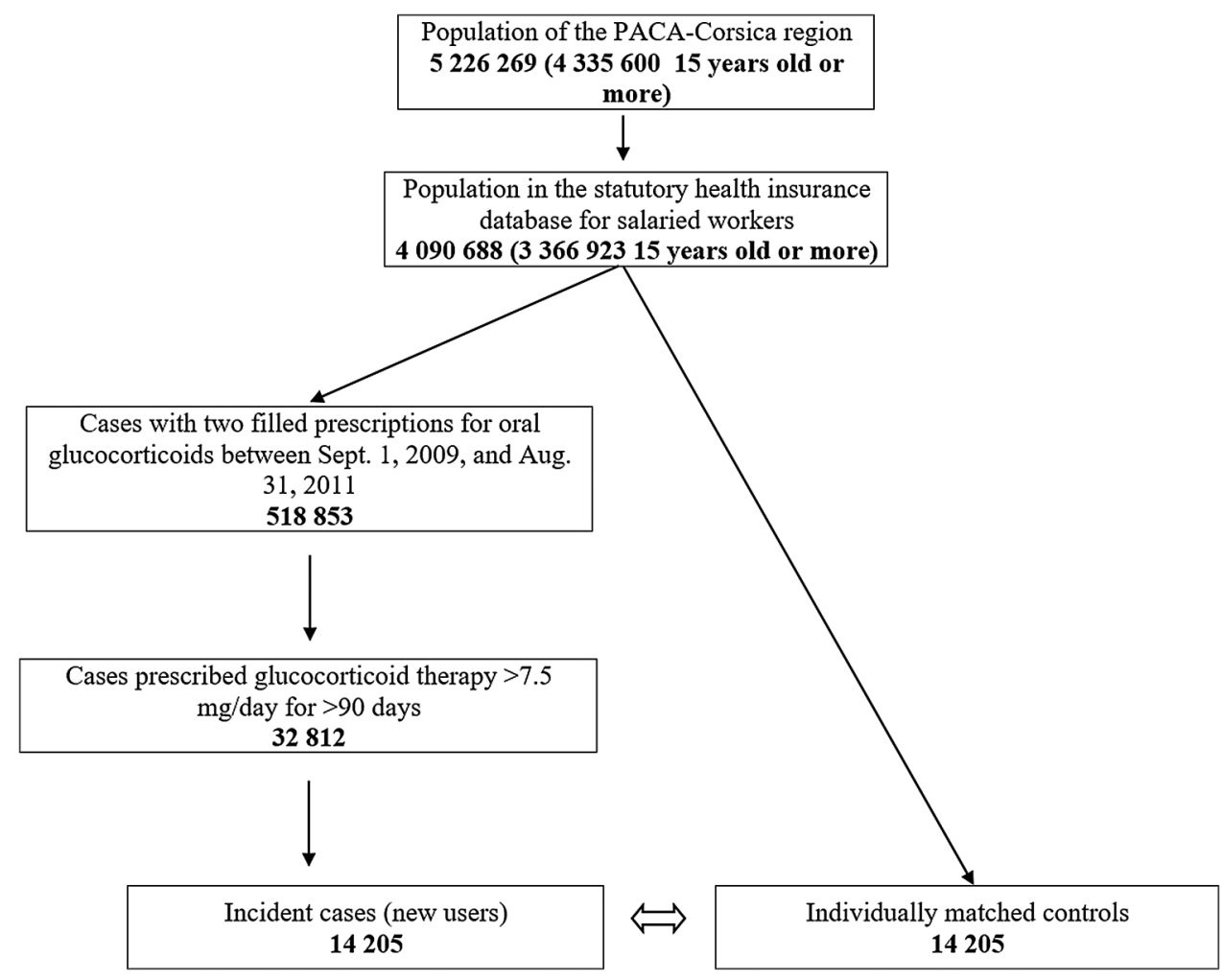

Figure 1 Flow chart of study patient selection. PACA, Provence Alpes Côtes d'azur. 
Table 1 Prescriptions of dual-energy X-ray absorptiometry (DXA), supplements and osteoporosis medications, in cases with incident glucocorticoid therapy and in controls

\begin{tabular}{|c|c|c|c|c|c|c|c|c|}
\hline & \multicolumn{2}{|c|}{ Overall population } & \multicolumn{2}{|l|}{ All males } & \multicolumn{2}{|l|}{ All females } & \multicolumn{2}{|c|}{ Females $>55$ years } \\
\hline & Cases & Controls & Cases & Controls & Cases & Controls & Cases & Controls \\
\hline DXA & $1175(8.3)^{\star}$ & $421(3)$ & $184(3)^{\star}$ & $19(0.3)$ & $991(12.5)^{\star}$ & $402(5.1)$ & $820(18.7)^{\star}$ & $353(8.1)$ \\
\hline Calcium + vitamin D & $2542(17.9)^{*}$ & $559(3.9)$ & $780(12.4)^{\star}$ & $49(0.8)$ & $1762(22.3)^{\star}$ & $510(6.5)$ & $1336(30.5)^{*}$ & $470(10.7)$ \\
\hline Bisphosphonates & $1729(12.2)^{*}$ & $355(2.5)$ & $506(8.0)^{*}$ & $23(0.4)$ & $1223(15.5)^{\star}$ & $332(4.2)$ & $1054(24.1)^{*}$ & 325 (7.4) \\
\hline Any treatment & $5137(36.2)^{*}$ & 1646 (11.6) & $1660(26.3)^{\star}$ & $258(4.1)$ & $3477(44)^{*}$ & 1388 (17.6) & $2554(58.4)^{\star}$ & 1195 (27.3) \\
\hline
\end{tabular}

public hospital (on an inpatient or outpatient basis). The main underlying health conditions associated with glucocorticoid prescriptions were rheumatoid arthritis (20\%); autoimmune disease defined as systemic lupus erythematosus, polyarteritis nodosa or Sjögren's syndrome (13\%); chronic respiratory failure (13\%); asthma $(10 \%)$; and chronic inflammatory bowel disease (Crohn's disease or ulcerative colitis, $8 \%$ ).

\section{Factors associated with prescription of absorptiometry and} osteoporosis treatment

By multivariate analysis, variables showing independent positive associations with DXA were female gender (aOR 5.1) $\left(\mathrm{p}<10^{-6}\right)$, age older than 55 years (aOR 3.9) $\left(\mathrm{p}<10^{-6}\right)$ and glucocorticoid therapy initiated by a rheumatologist (aOR 3.9) $\left(\mathrm{p}<10^{-6}\right)$. These results are detailed in table 2. The highest DXA prescription rate, found in women older than 55 years treated by rheumatologists, only reached $39 \%$ (table 3 ).

Similarly, prescription of osteoporosis treatment showed independent positive associations with female gender, age older than 55 years, initiation of glucocorticoid therapy by a rheumatologist, autoimmune disease as the underlying diagnosis and prescription of DXA (tables 1 and 2 and see online supplementary table S4). There was a significant dose effect in prescription of bisphosphonates by dosage of prednisone. The results showed a significant linear increase of probability of treatment by bisphosphonate with the increase of prednisone dosage (respectively 7\%,12\%, 16\%, 19\% and $21 \%$ for the corresponding classes of prednisone dosage $7.5-10 ; 10-15 ; 15-20,20-30$ and more than $30 \mathrm{mg})$. At least one osteoporosis treatment (osteoporosis medication and/or calcium and vitamin D) was prescribed to $58 \%$ of women over 55 years of age and $26 \%$ of men. Rates of calcium associated with vitamin D supplement prescription ranged from $15 \%$ among primary care physicians to $37 \%$ among gastroenterologists, rates of bisphosphonate prescription from 10\% among primary care physicians to $28 \%$ among rheumatologists and rates of prescription of any osteoporosis treatment from $31 \%$ among primary care physicians to $65 \%$ among

Table 2 Factors associated with prescription of DXA, calcium and vitamin D supplements, and osteoporosis medications

\begin{tabular}{|c|c|c|}
\hline & $\begin{array}{l}\text { DXA performed } \\
\text { Adjusted OR }(\mathrm{Cl})\end{array}$ & $\begin{array}{l}\text { Any treatment delivered } \\
\text { Adjusted OR }(\mathrm{Cl})\end{array}$ \\
\hline Female (vs male) & $5.1(4.3 \text { to } 6.0)^{*}$ & $2.3(2.1 \text { to } 2.5)^{*}$ \\
\hline Age $>55$ years (vs age $\leq 55$ years) & $3.9(3.3 \text { to } 4.6)^{*}$ & $2.7(2.5 \text { to } 2.9)^{*}$ \\
\hline Specialty of initial GC prescriber (vs PCP) & * & * \\
\hline Rheumatologist & $3.0(2.4 \text { to } 3.7)^{\star}$ & $2.5(2.1 \text { to } 3.0)^{*}$ \\
\hline Pulmonologist & $1.0(0.6 \text { to } 1.5)^{\mathrm{NS}}$ & $0.9(0.7 \text { to } 1.2)^{\mathrm{NS}}$ \\
\hline Gastroenterologist & $1.3(0.7 \text { to } 2.5)^{\mathrm{NS}}$ & $1.7(1.2 \text { to } 2.3)^{\delta}$ \\
\hline Internist & $1.4(0.7 \text { to } 2.5)^{\mathrm{NS}}$ & $2.2(1.5 \text { to } 3.3)^{\delta}$ \\
\hline Other & $1.2(0.9 \text { to } 1.4)^{\mathrm{NS}}$ & $1.0(0.9 \text { to } 1.1)^{\mathrm{NS}}$ \\
\hline Not recorded $\dagger$ & $1.2(1.1 \text { to } 1.5)^{\delta}$ & $1.5(1.3 \text { to } 1.6)^{\star}$ \\
\hline Mean GC dosage $>15 \mathrm{mg} /$ day (vs $\leq 15 \mathrm{mg} /$ day) & $1.1(0.9 \text { to } 1.2)^{*}$ & $1.8(1.7 \text { to } 2.0)^{*}$ \\
\hline RA (vs other diagnoses) & $2.0(1.5 \text { to } 2.5)^{*}$ & $2.6(2.2 \text { to } 3.2)^{*}$ \\
\hline Chronic respiratory failure (vs other diagnoses) & $0.5(0.3 \text { to } 0.9)^{\delta}$ & $1.3(1.0 \text { to } 1.6)^{\mathrm{NS}}$ \\
\hline Autoimmune disease $\neq$ (vs other diagnoses) & $2.4(1.9 \text { to } 3.1)^{*}$ & $4.7(3.6 \text { to } 6.1)^{\star}$ \\
\hline Asthma (vs other diagnoses) & $1.0(0.6 \text { to } 1.7)^{\mathrm{NS}}$ & $1.1(0.8 \text { to } 1.5)^{\mathrm{NS}}$ \\
\hline IBD (vs other diagnoses) & $1.2(0.7 \text { to } 2.0)^{\mathrm{NS}}$ & $2.2(1.7 \text { to } 2.8)^{\star}$ \\
\hline DXA performed (vs not performed) & & $4.6(4.0 \text { to } 5.4)^{\star}$ \\
\hline \multicolumn{3}{|c|}{$\begin{array}{l}{ }^{*} \mathrm{p}<10^{-6},{ }^{\delta} \mathrm{p}<0.05 \text {. } \\
\text { †Specialty of hospital-based physicians was not recorded in the database. } \\
\text { †Defined in this study as systemic lupus erythematosus, Sjögren's syndrome and polyarteritis nodosa. } \\
\text { DXA, dual-energy X-ray absorptiometry; GC, glucocorticoid; IBD, inflammatory bowel disease; NS, non-significant; PCP, primary care } \\
\text { physician: RA, rheumatoid arthritis. }\end{array}$} \\
\hline
\end{tabular}


Table 3 Use of dual-energy X-ray absorptiometry according to initial glucocorticoid prescriber and underlying diagnosis

\begin{tabular}{|c|c|c|c|}
\hline & $\begin{array}{l}\text { Overall population } \\
n=14205 \\
n(\%)\end{array}$ & $\begin{array}{l}\text { Women }<55 \text { years } \\
\text { and Men } \\
n=9828 \\
\mathrm{n}(\%)\end{array}$ & $\begin{array}{l}\text { Women }>55 \text { years } \\
n=4377 \\
n(\%)\end{array}$ \\
\hline \multicolumn{4}{|l|}{ Prescriber's specialty } \\
\hline Primary-care physician & $545(6.9)$ & $154(2.8)$ & $391(16.4)^{\star}$ \\
\hline Rheumatologist & $182(24.9)$ & $44(11.8)$ & $138(38.8)^{\star}$ \\
\hline Pulmonologist & $20(5.9)$ & $6(2.4)$ & $14(14.7)^{\delta}$ \\
\hline Gastroenterologist & $14(6.3)$ & $10(5.1)$ & $4(14.3)^{N S}$ \\
\hline Internist & $13(11.5)$ & $5(7.4)$ & $8(17.8)^{\mathrm{NS}}$ \\
\hline Other & $167(10.1)$ & $34(2.9)$ & $86(18.8)^{\star}$ \\
\hline Not recorded ${ }^{\dagger}$ & $281(8.5)$ & $102(4.5)$ & $179(17.8)^{\star}$ \\
\hline \multicolumn{4}{|l|}{ Diagnosis $^{\ddagger}$} \\
\hline Rheumatoid arthritis & $120(21.8)$ & $31(11.3)$ & $89(32.2)^{*}$ \\
\hline Autoimmune disease $\mathrm{e}^{\S}$ & $99(25.3)$ & $18(10.7)$ & $81(36.2)^{*}$ \\
\hline Chronic respiratory failure & $21(4.9)$ & $5(1.8)$ & $16(10.7)^{\delta}$ \\
\hline Asthma & $20(8.9)$ & $4(3.1)$ & $16(16.3)^{\delta}$ \\
\hline Inflammatory bowel disease & $24(6.5)$ & $17(5.3)$ & $7(13.5)^{\mathrm{NS}}$ \\
\hline \multicolumn{4}{|c|}{$\begin{array}{l}\text { Comparison between Women }<55 \text { years and men versus Women }>55 \text { years. } \\
\text { NS Non significant, }{ }^{*} \mathrm{p}<10^{-6},{ }_{\mathrm{p}} \mathrm{p}<0.05 \\
\text { †Specialty of hospital-based physicians was not recorded in the database. } \\
\text { fOther diagnoses than RA, autoimmune diseases, Chronic respiratory failure, asthma and IBD were miscellaneous conditions with small } \\
\text { numbers or unknown. } \\
\text { §Defined in this study as systemic lupus erythematosus, Sjögren's syndrome, and polyarteritis nodosa. }\end{array}$} \\
\hline
\end{tabular}

rheumatologists. At least one osteoporosis treatment was prescribed in $80 \%$ of cases with autoimmune diseases, $36 \%$ of cases with asthma and $36 \%$ of cases overall. The rate of calcium associated with vitamin $\mathrm{D}$ supplement prescription ranged from $16 \%$ in cases with asthma to $58 \%$ in those with autoimmune disease, and the rate of bisphosphonate prescription ranged from $5 \%$ in patients with chronic inflammatory bowel disease to $41 \%$ in those with autoimmune disease.

In the group with DXA prescription, the proportions of patients with prescriptions for calcium associated with vitamin D supplements, bisphosphonates and any treatment were $47 \%, 35 \%$ and $79 \%$, respectively; corresponding proportions in the group without DXA prescription were $15 \%, 10 \%$ and $32 \%$. The rate of prescription of any osteoporosis treatment was highest $(81 \%)$ among women older than 55 years with DXA prescription and lowest $(20 \%)$ in men whose glucocorticoid treatment had been initiated by a primary care physician.

\section{DISCUSSION}

Our study population can be considered as a representative sample of the French population and our data confirm our hypothesis that the management of GIOP is suboptimal, despite the existence of published recommendations. The $1 \%$ prevalence of long-term glucocorticoid therapy was consistent with previous studies showing prevalence of $0.5-0.9 \%$ overall, and of up to $2.5 \%$ in the 70-79 year age group. ${ }^{1-3}$ Although DXA and osteoporosis treatment prescription rates were substantially higher among the cases than among the controls, they were markedly inadequate. Despite a mean prednisone-equivalent dosage of $11 \mathrm{mg} /$ day, only $8 \%$ of cases underwent DXA and only $25 \%$ were prescribed calcium associated with vitamin D supplements, $19 \%$ a bisphosphonate and $45 \%$ any treatment. In women older than 55 years-the group at highest risk-only $19 \%$ underwent DXA and only $58 \%$ were prescribed an osteoporosis treatment. Corresponding rates in men were $3 \%$ and $26 \%$.

Our findings are consistent overall with those obtained previously in various countries. ${ }^{1}{ }^{2}{ }^{14-26}$ The DXA prescription rates in our population are in line with several published studies reporting rates of about $6 \%$ in men and women younger than 50 years of age and of up to $16 \%-19 \%$ in women older than 50 years of age. ${ }^{1522} 23$ The low DXA prescription rate is of concern, since DXA showed the strongest association with treatment prescription, with an aOR of 4.6. The role of DXA as a trigger for treatment to prevent or control osteoporosis has been well established. ${ }^{22}$ In France, DXA is widely available, as it can be performed by rheumatologists and radiologists. DXA costs $€ 40$ and is almost fully reimbursed, so it cannot explain the low rate of individuals with a DXA measurement.

In previously published studies that also confined the analysis to incident cases of glucocorticoid therapy, the rates of calcium associated with vitamin $\mathrm{D}$ supplementation were not recorded. ${ }^{26-28}$ Other studies analysed all glucocorticoid-treated patients and found calcium associated with vitamin $\mathrm{D}$ supplementation rates ranging from $30 \%$ to $51 \%$. These higher rates compared with our results may be ascribable to methodological differences. ${ }^{14} 162225$ A study of incident cases showed lower bisphosphonate prescription rates than in our population, of $8 \%$ overall and $16 \%$ in women over 55 years, 
compared with $12 \%$ and $24 \%$ in our study, respectively. Another study of all patients given glucocorticoid therapy also found a slightly lower rate, of $7 \% .^{20}{ }^{23}$ The rates of prescription of any treatment in our study are difficult to compare to previously published data, since we excluded oestrogen therapy from our list of osteoporosis medications. In studies that included oestrogen replacement therapy, rates of prescription of any treatment ranged from $21 \%$ to $58 \%$, compared with $36 \%$ in our population. ${ }^{1417202324}$

A small improvement in GIOP management rates between 1998 and 2008 has been reported. ${ }^{15}$ Nevertheless, even in recent studies, rates remained markedly inadequate. ${ }^{14} 15$

In our study, treatment prescription rates were associated with the specialty of the physician who initiated glucocorticoid therapy and with the underlying diagnosis. Treatment prescription rates were highest when the initial prescriber was a rheumatologist, with $25 \%$ of patients receiving DXA and $65 \%$ treatment prescriptions; and when the underlying diagnosis was an autoimmune disease (systemic lupus erythematosus, Sjögren's syndrome, or polyarteritis nodosa). When specified, better management of GIOP by rheumatologists was consistently found. ${ }^{152123}$

One of the strengths of our study lies in the collection of data from an entire population as opposed to a sample. In France, $75 \%$ of individuals are covered by a single statutory health insurance system. In addition, in patients who have chronic diseases, this health insurance system reimburses the full cost of both, DXA and treatments (including the supplements and medications of interest in our study). Thus, there are no financial obstacles to adequate management, and all filled prescriptions are recorded in the health insurance database. Out-of-pocket purchases of treatments (including calcium and vitamin D supplements) are extremely uncommon. Another strong point of our study is that only incident cases of glucocorticoid therapy were included in the analysis. The bone loss induced by glucocorticoids occurs early and at a fast pace, being significant within 6 months. Consequently, an evaluation of bone risk and the implementation of prophylactic measures should take place at, or shortly after, the first prescription of glucocorticoid therapy.

Our study also exhibits some weaknesses. First, the database had no information on the specialties of physicians working in publicly funded hospitals, who comprised $22 \%$ of initial glucocorticoid prescribers. This point explains the small proportion of internists in our study, as most internists work full-time in hospitals. Initial glucocorticoid therapy prescription by a hospital-based physician was associated with slightly higher prescription rates of supplements and osteoporosis medications, compared with initial prescription by a community-based physician. Second, the data were anonymised and we had no information allowing us to determine which individuals met criteria for the prescription of antiresorptive therapy.
Indeed, we had no information on osteoporosis risk factors such as body mass index, family or personal history of fracture, nor on fall risk factors such as comorbidity and living conditions. However, the rate of calcium-associated vitamin D prescription should have been close to $100 \%$ but was only $18 \%$, despite a mean patient age of 58 years and a mean daily prednisone-equivalent dosage of $11 \mathrm{mg}$.

Targeted interventions are required in order to improve GIOP. A simple mailing intervention programme that screened at-risk patients and reached out to these patients and their physicians was associated with a modest increase in the proportion of at-risk patients receiving preventive drug therapy for osteoporosis. ${ }^{29}$ Online educational video did not improve the prescription of preventive drug therapy for osteoporosis. ${ }^{30} 31$ Pharmacists could be involved to inform patients and physicians. However, active identification of patients eligible for GIOP by pharmacists did not significantly increase the prescribing of bisphosphonates in a randomised trial. ${ }^{32}$ New tools should be developed to improve physician and patient concerns about GIOP. It would be of interest to develop medications that associate corticosteroids with antiosteoporotic drugs. New French GIOP guidelines have recently been published, ${ }^{13}$ we hope this will improve GIOP management.

\section{CONCLUSION}

The results of our study conducted in 2009-2011 in a population of a large region of France are consistent with those of all other published international studies: the management of GIOP remains very inadequate, despite the availability of a statutory health insurance system. Inadequacies are particularly marked among primary care physicians, who comprise the largest proportion of initial glucocorticoid prescribers and play a crucial role in patient follow-up. In addition, we have no information on adherence to delivered treatments. Our data indicate a pressing need for targeted interventions designed to improve the management of GIOP.

\section{Author affiliations}

${ }^{1}$ Service de Rhumatologie, APHM, Hôpital Sainte-Marguerite, Marseille, France

${ }^{2}$ Faculté de Médecine, Aix-Marseille Université, Marseille, France

${ }^{3}$ Service de Santé Publique et d'Information Médicale, APHM, Hôpital

Sainte-Marguerite, Marseille, France

${ }^{4}$ Direction Régionale du Service Médical du Régime Général de l’Assurance Maladie Paca Corse, Marseille, France

Competing interests None declared.

Provenance and peer review Not commissioned; externally peer reviewed.

Data sharing statement Unpublished data can be obtained by contacting the corresponding author.

Open Access This is an Open Access article distributed in accordance with the Creative Commons Attribution Non Commercial (CC BY-NC 4.0) license, which permits others to distribute, remix, adapt, build upon this work noncommercially, and license their derivative works on different terms, provided the original work is properly cited and the use is non-commercial. See: http:// creativecommons.org/licenses/by-nc/4.0/ 


\section{REFERENCES}

1. Overman RA, Yeh JY, Deal CL. Prevalence of oral glucocorticoid usage in the United States: a general population perspective. Arthritis Care Res (Hoboken) 2013;65:294-8.

2. Gudbjornsson B, Juliusson UI, Gudjonsson FV. Prevalence of long term steroid treatment and the frequency of decision making to prevent steroid induced osteoporosis in daily clinical practice. Ann Rheum Dis 2002;61:32-6.

3. Fardet L, Petersen I, Nazareth I. Prevalence of long-term oral glucocorticoid prescriptions in the UK over the past 20 years. Rheumatology (Oxford) 2011;50:1982-90.

4. van Staa TP, Leufkens HG, Cooper C. The epidemiology of corticosteroid induced osteoporosis: a meta-analysis. Osteoporosis Int 2002;13:777-87.

5. Saag KG. Glucocorticoid-induced osteoporosis. Endocrinol Metab Clin North Am 2003;32:135-57, vii.

6. Briot K, Roux C. Glucocorticoid-induced osteoporosis. RMD Open 2015;1:e000014.

7. Roux C. Osteoporosis in inflammatory joint diseases. Osteoporosis Int 2011;22:421-33.

8. Silverman S, Curtis J, Saag K, et al. International management of bone health in glucocorticoid-exposed individuals in the observational GLOW study. Osteoporosis Int 2015;26: 419-20.

9. Grossman JM, Gordon R, Ranganath VK, et al. American College of Rheumatology 2010 recommendations for the prevention and treatment of glucocorticoid-induced osteoporosis. Arthritis Care Res (Hoboken) 2010;62:1515-26.

10. Recommendations for the prevention and treatment of glucocorticoid-induced osteoporosis: 2001 update. American College of Rheumatology Ad Hoc Committee on Glucocorticoid-Induced Osteoporosis. Arthritis Rheum 2001;44: 1496-503.

11. AFSSAPS (Agence Française de Sécurité Sanitaire des Produits de santé), France. Traitement médicamenteux de l'ostéoporose cortisonique. Recommandations de bonne pratique [In French]. 2003. http://www.soc-nephrologie.org/PDF/enephro/ recommandations/Afssaps/2003/osteoporose_cortisonique.pdf

12. HAS (Haute Autorité de la Santé). Prévention, diagnostic et traitement de l'ostéoporose. Note de synthèse Juillet 2006 [In French]. 2006. http://www.has-sante.fr/portail/upload/docs/ application/pdf/osteoporose_synthese.pd

13. Briot K, Cortet B, Roux C, et al. Bone Section of the French Society for Rheumatology (SFR) and Osteoporosis Research and Information Group (GRIO). 2014 update of recommendations on the prevention and treatment of glucocorticoid-induced osteoporosis. Joint Bone Spine 2014;81:493-501.

14. Massafra U, Migliaccio S, Bancheri $C$, et al. Approach in glucocorticoid induced osteoporosis (GIO) prevention: results from the Italian multicenter observational EGEO Study. J Endocrinol Invest 2013;36:92-6.

15. Majumdar SR, Lix LM, Yogendran M, et al. Population-based trends in osteoporosis management after new initiations of long-term systemic glucocorticoids (1998-2008). J Clin Endocrinol Metab 2012;97:1236-42.

16. Sadat-Ali M, Alelq AH, Alshafei BA, et al. Osteoporosis prophylaxis in patients receiving chronic glucocorticoid therapy. Ann Saudi Med 2009;29:215-18.

17. Solomon DH, Brookhart MA, Gandhi TK, et al. Adherence with osteoporosis practice guidelines: a multilevel analysis of patient physician, and practice setting characteristics. Am J Med 2004;117:919-24.

18. Curtis JR, Westfall AO, Allison JJ, et al. Longitudinal patterns in the prevention of osteoporosis in glucocorticoid-treated patients. Arthritis Rheum 2005;52:2485-94.

19. Feldstein AC, Elmer PJ, Nichols GA, et al. Practice patterns in patients at risk for glucocorticoid-induced osteoporosis. Osteoporos Int 2005;16:2168-74.

20. Buckley LM, Marquez M, Feezor R, et al. Prevention of corticosteroid-induced osteoporosis: results of a patient survey. Arthritis Rheum 1999;42:1736-9.

21. Yood RA, Harrold LR, Fish L, et al. Prevention of glucocorticoid-induced osteoporosis: experience in a managed care setting. Arch Intern Med 2001;161:1322-7.

22. Saag KG, Gehlbach SH, Curtis JR, et al. Trends in prevention of glucocorticoid-induced osteoporosis. J Rheumatol 2006;33: 1651-7.

23. Mudano A, Allison J, Hill J, et al. Variations in glucocorticoid induced osteoporosis prevention in a managed care cohort. J Rheumatol 2001;28:1298-305.

24. Aagaard EM, Lin P, Modin GW, et al. Prevention of glucocorticoid-induced osteoporosis: provider practice at an urban county hospital. Am J Med 1999;107:456-60.

25. Gera C, Vij AS. Glucocorticoid-induced osteoporosis: unawareness or negligence in India? Int J Rheum Dis 2009;12:230-3.

26. Cummings SR, Melton LJ. Epidemiology and outcomes of osteoporotic fractures. Lancet 2002;359:1761-7.

27. Harvey N, Dennison E, Cooper C. Osteoporosis: impact on health and economics. Nat Rev Rheumatol 2010;6:99-105.

28. Fukui N, Watanabe $\mathrm{Y}$, Nakano $\mathrm{T}$, et al. Predictors for ambulatory ability and the change in ADL after hip fracture in patients with different levels of mobility before injury: a 1-year prospective cohort study. J Orthop Trauma 2012;26:163-71.

29. Chitre MM, Hayes W. 3-year results of a member and physician intervention to reduce risk associated with glucocorticoid-induced osteoporosis in a health plan. J Manag Care Pharm 2008;14: 281-90.

30. Warriner $\mathrm{AH}$, Outman RC, Allison JJ, et al. An internet-based controlled trial aimed to improve osteoporosis prevention among chronic glucocorticoid users. J Rheumatol 2015;42:1478-83.

31. Curtis JR, Westfall AO, Allison J, et al. Challenges in improving the quality of osteoporosis care for long-term glucocorticoid users: a prospective randomized trial. Arch Intern Med 2007;167:591-6.

32. Klop C, de Vries F, Vinks T, et al. Increase in prophylaxis of glucocorticoid-induced osteoporosis by pharmacist feedback: a randomised controlled trial. Osteoporos Int 2014;25:385-92. 